\title{
Cerebrovascular risk factors associated with ischemic stroke in a young non-diabetic and non-hypertensive population: a retrospective case-control study
}

\author{
Nan Zhang, Lin Zhang, Qiu Wang, Jingwei Zhao, Jia Liu* and Guang Wang ${ }^{*}$ (D)
}

\begin{abstract}
Background: Globally, rates of ischemic stroke (IS) have been rising among young adults. This study was designed to identify risk factors associated with IS incidence in young adults unaffected by hypertension or diabetes.

Methods: This was a retrospective case-control study of early-onset IS patients without diabetes and hypertension. Control patients were matched with healthy individuals based upon sex, age ( \pm 2 years), and $\mathrm{BMI}\left( \pm 3 \mathrm{~kg} / \mathrm{m}^{2}\right)$ at a $1: 3$ ratio. Sociodemographic, clinical, and risk factor-related data pertaining to these patients was collected. The association between these risk factors and IS incidence was then assessed using conditional logistic regression models.

Results: We recruited 60 IS patients and 180 controls with mean ages of $44.37 \pm 4.68$ and $44.31 \pm 4.71$ years, respectively, for this study. Relative to controls, IS patients had significantly higher total cholesterol (TG), homocysteine (HCY), white blood cell (WBC), absolute neutrophil count (ANC), systolic blood pressure (SBP), and diastolic blood pressure (DBP) levels, and significantly lower high-density lipoprotein cholesterol (HDL-C) and triglyceride cholesterol (TC), free triiodothyronine (FT3), and free thyroxine (FT4) levels (all $P<0.05)$. After controlling for potential confounding factors, $\mathrm{HCY}$ and ANC were found to be significantly positively associated with IS incidence (OR 1.518, 95\%Cl 1.165-1.977, $P=0.002$ and $\mathrm{OR} 2.418,95 \% \mathrm{Cl} 1.061-5.511, P=0.036$, respectively), whereas $\mathrm{HDL}-\mathrm{C}$ and FT3 levels were negatively correlated with IS incidence (OR $0.001,95 \% \mathrm{Cl} 0.000-0.083, P=0.003$ and $\mathrm{OR}$ $0.053,95 \% \mathrm{Cl} 0.008-0.326, P=0.002$, respectively).

Conclusions: In young non-diabetic and non-hypertensive patients, lower HDL-C and FT3 levels and higher HCY and ANC levels may be associated with an elevated risk of IS. Additional prospective studies of large patient cohorts will be essential to validate these findings.
\end{abstract}

Keywords: Ischemic stroke, Risk factors, Young adults, Early-onset, Young-onset

*Correspondence: liujia0116@126.com; drwg6688@126.com Department of Endocrinology, Beijing Chao-yang Hospital, Capital Medical University, Beijing 100020, China

C C The Author(s). 2020 Open Access This article is licensed under a Creative Commons Attribution 4.0 International License, which permits use, sharing, adaptation, distribution and reproduction in any medium or format, as long as you give appropriate credit to the original author(s) and the source, provide a link to the Creative Commons licence, and indicate if changes were made. The images or other third party material in this article are included in the article's Creative Commons licence, unless indicated otherwise in a credit line to the material. If material is not included in the article's Creative Commons licence and your intended use is not permitted by statutory regulation or exceeds the permitted use, you will need to obtain permission directly from the copyright holder. To view a copy of this licence, visit http://creativecommons.org/licenses/by/4.0/ The Creative Commons Public Domain Dedication waiver (http://creativecommons.org/publicdomain/zero/1.0/) applies to the data made available in this article, unless otherwise stated in a credit line to the data. 


\section{Background}

Ischemic stroke (IS) is a serious condition associated with high morbidity and mortality rates throughout the world. Between 10 and 18\% of IS episodes first occur in persons under the age of $50[1,2]$, and such incidence is termed early/young-onset stroke or stroke in young adults [3-5]. IS incidence in younger adults can incur high healthcare costs and can significantly decrease labor productivity [6]. As rates of IS among young adults are rising faster than rates among older adults, the global burden associated with this condition is likely to continue rising in the immediate future $[7,8]$.

Traditionally, risk factors associated with over $80 \%$ of IS incidence among young adults include smoking, hypertension, obesity, diabetes, and dyslipidemia, ${ }^{9}$ with approximately 10 and $35 \%$ of these patients being affected by diabetes and hypertension, respectively $[9,10]$. Diabetes and its cardiovascular events have a clear inflammatory pathogenesis involved with an adiposeinflammatory vascular axis predisposing to atherosclerosis [11], oxidative stress [12] and atrial fibrillation due to cardiac nervous autonomic dysfunction [13]. Moreover, hypertension can increase the risk of these diabetic vascular complications [14]. Even patients unaffected by these conditions still suffer from IS in some cases, however, with roughly $33 \%$ of IS cases in this age group being cryptogenous [15]. Identifying risk factors associated with IS in these patients may facilitate better preventative or interventional treatment. As such, the present study was designed to identify risk factors associated with IS incidence in young adults unaffected by hypertension and diabetes.

\section{Methods}

\section{Study design and participants}

Between March and October 2019, 60 non-diabetic and non-hypertensive inpatients at Beijing Chao-yang Hospital that had suffered their first-ever incidence of acute IS were recruited for this study (age: $32-50$ years). IS as defined as sudden onset neurological dysfunction associated with an infarcted site that was detected via brain magnetic resonance imaging (MRI). A healthy control population that was matched according to age $( \pm 2$ years), sex, and BMI $\left( \pm 3.0 \mathrm{~kg} / \mathrm{m}^{2}\right)$ were recruited randomly from among patients undergoing physical examinations at our hospital. Recruitment was conducted at a 1:3 case to control ratio. Patients were excluded from this study if they suffered from known hypertension, diabetes, cancer, autoimmunity, thyroid disease, encephalitis, head trauma, cerebral hemorrhage, severe multiple organ dysfunction, infections, severe liver or kidney diseases, or pregnancy. The Medical Ethics Committee of Beijing Chaoyang Hospital approved this study, which was consistent with the Declaration of Helsinki, and the requirement for written informed consent was waived due to the retrospective design. Patient data have been de-identified upon data collection.

\section{Measurements}

For all patients, the following data were recorded: sex, age, BMI, smoking status, SBP, DBP, fasting blood glucose (FBG), creatinine (CR), uric acid (UA), HCY, TC, TG, HDL-C, low-density lipoprotein cholesterol (LDLC), FT3, FT4, and thyroid-stimulating hormone (TSH) levels, as well as WBC, ANC, absolute lymphocyte count (ALC), platelet (PLT), and hemoglobin (HGB) values. All IS patients underwent routine testing include brain MRI scans, chest X-ray, and cardiac tests including electrocardiography and transthoracic echocardiograms in an effort to detect any potential atrial fibrillation, ischemic heart disease, or rheumatic heart disease. Other testing was conducted as appropriate in order to ensure that patients met with study inclusion/exclusion criteria.

Following overnight fasting, blood samples were collected from the antecubital vein of each patient and were analyzed with an Abbott Architect i2000 (Abbott Diagnostics, IL, USA). The same medical staff measured the weight and height of all patients, and BMI (in $\mathrm{kg} / \mathrm{m}^{2}$ ) was calculated based on these values. The same $3.0 \mathrm{~T}$ Siemens scanner (Erlangen, Germany) was used for all MRI scans.

\section{Statistical analysis}

SPSS 24.0 (SPSS, IL, USA) was used for all statistical testing. The Kolmogorov-Smirnov test was used to assess the normality of distributed data, with normally and non-normally distributed data being expressed as means \pm standard deviation (SD) and medians with interquartile ranges (IQR). Data were compared between case and control groups using chi-squared tests, Student's t-tests, or Mann-Whitney $U$ tests as appropriate, and univariate odds ratios (ORs) for these risk factors were calculated. Those risk factors that were significantly associated with IS incidence in univariate analyses were then incorporated into a multivariate conditional logistic regression model, after which adjusted ORs and 95\% confidence intervals were estimated. For this model, a forward stepwise logistic regression approach with a $P<0.10$ variable removal level was used. A two-sided $P<0.05$ was the significance threshold for this study.

\section{Results}

\section{Patient baseline characteristics}

Baseline data pertaining to the control and IS patient groups in this study are compiled in Table 1 . In total, $51 / 60$ IS patients were male, a history of cigarette smoking was reported in $68.3 \%$ of these patients, and the mean age at time of stroke was $44.31 \pm 4.71$ years. There 
Table 1 The baseline characteristics of the control and IS groups

\begin{tabular}{|c|c|c|c|}
\hline Parameters & $\begin{array}{l}\text { Control group } \\
(n=180)\end{array}$ & $\begin{array}{l}\text { IS group } \\
(n=60)\end{array}$ & $P$ \\
\hline Age, y & $44.31 \pm 4.71$ & $44.37 \pm 4.68$ & .918 \\
\hline BMl, $\mathrm{kg} / \mathrm{m}^{2}$ & $25.65 \pm 2.69$ & $25.86 \pm 2.57$ & .593 \\
\hline Gender, Females/Males & $27 / 153$ & $9 / 51$ & 1.000 \\
\hline Smoker/non-smoker & 0 & $41 / 19$ & .000 \\
\hline $\mathrm{FT} 3, \mathrm{pmol} / \mathrm{L}$ & $5.42 \pm 0.54$ & $4.72 \pm 0.69$ & .000 \\
\hline $\mathrm{FT} 4, \mathrm{pmol} / \mathrm{L}$ & $16.38 \pm 2.18$ & $12.26 \pm 2.91$ & .000 \\
\hline $\mathrm{TSH}, \mathrm{mIU} / \mathrm{L}$ & $1.79(0.59-5.38)$ & $1.58(0.23-6.5)$ & .548 \\
\hline $\mathrm{HDL}-\mathrm{C}, \mathrm{mmol} / \mathrm{L}$ & $1.16(0.69-2.29)$ & $0.95(0.62-1.59)$ & .000 \\
\hline LDL-C, mmol/L & $2.80 \pm 0.65$ & $2.72 \pm 0.91$ & .117 \\
\hline $\mathrm{TC}, \mathrm{mmol} / \mathrm{L}$ & $4.97 \pm 0.78$ & $4.39 \pm 1.08$ & .000 \\
\hline $\mathrm{TG}, \mathrm{mmol} / \mathrm{L}$ & $1.41(0.43-3.85)$ & $1.58(0.61-6.25)$ & .032 \\
\hline $\mathrm{FBG}, \mathrm{mmol} / \mathrm{L}$ & $5.49 \pm 0.50$ & $5.48 \pm 1.06$ & .080 \\
\hline$C R, \mu \mathrm{mol} / \mathrm{L}$ & $69.79 \pm 11.82$ & $68.45 \pm 11.68$ & .289 \\
\hline UA, $\mu \mathrm{mol} / \mathrm{L}$ & $337.33(145.00-473.95)$ & $325.50(191.00-542.00)$ & .445 \\
\hline $\mathrm{HCY}, \mu \mathrm{mol} / \mathrm{L}$ & $10.42(6.25-17.83)$ & $16.08(5.00-136.87)$ & .000 \\
\hline WBC, $10^{9} / \mathrm{L}$ & $6.04(3.28-10.09)$ & $7.03(4.50-19.6)$ & .001 \\
\hline ANC, $10^{9} / \mathrm{L}$ & $3.40(1.18-6.60)$ & $4.18(2.26-17.70)$ & .000 \\
\hline $\mathrm{ALC}, 10^{9} / \mathrm{L}$ & $2.05(0.78-4.76)$ & $2.08(1.02-4.90)$ & .949 \\
\hline $\mathrm{HGB}, \mathrm{g} / \mathrm{L}$ & $151.12 \pm 14.97$ & $148.17 \pm 16.81$ & .097 \\
\hline $\mathrm{PLT}, 10^{9} / \mathrm{L}$ & $217.23 \pm 42.66$ & $231.43 \pm 56.99$ & .109 \\
\hline $\mathrm{SBP}, \mathrm{mmHg}$ & $123.41 \pm 13.07$ & $137.63 \pm 17.89$ & .000 \\
\hline $\mathrm{DBP}, \mathrm{mmHg}$ & $77.20 \pm 10.73$ & $85.87 \pm 12.81$ & .000 \\
\hline
\end{tabular}

Data are means \pm S.D. unless indicated otherwise. TSH, HDL-C, TG, UA, HCY, WBC, ANC and ALC are shown as median, upper and lower quartiles. $P$ : the stroke group vs the control group, analyzed by chi-square test, independent Student's t-test or the Mann-Whitney test using SPSS 24.0. IS, ischemic stroke; BMI body mass index; FT3 free triiodothyronine; FT4 free thyroxine; TSH thyroid-stimulating hormone; HDL-C high-density lipoprotein cholesterol; LDL-C low-density lipoprotein cholesterol; TC triglyceride cholesterol; TG total cholesterol; $F B G$ fasting blood glucose; $C R$ creatinine; UA uric acid; $H C Y$ Homocysteine; WBC white blood cell; ANC absolute neutrophil count; ALC absolute lymphocyte count; HGB hemoglobin, PLT platelet; SBP systolic blood pressure; DBP diastolic blood pressure

were no significant differences in age, sex, or BMI between these two patient groups, nor were any differences detected in serum TSH, LDL-C, FBG, CR, UA, ALC, HGB, or PLT when comparing these groups (all $P>$ 0.05). However, IS patients exhibited significantly lower HDL-C and TC levels relative to controls [0.95 (0.62$1.59)$ vs. $1.16(0.69-2.29) \mathrm{mmol} / \mathrm{L}, 4.39 \pm 1.08$ vs. $4.97 \pm$ $0.78 \mathrm{mmol} / \mathrm{L}$, respectively, $P<0.001$ ]. Levels of serum FT3 and FT4 were also significantly lower in IS patients relative to controls, while TG, $\mathrm{HCY}, \mathrm{WBC}, \mathrm{ANC}$, SBP, and DBP values were all significantly elevated among IS patients (all $P<0.05$ ).

Identification of risk factors associated with early-onset IS Univariate logistic regression analyses were initially used to identify risk factors associated with IS incidence (Table 2), revealing FT3, FT4, HDL-C, TC, TG, HCY, WBC, ANC, PLT, SBP, and DBP values to all be significantly associated with such incidence. Subsequent multivariate conditional logistic regression analysis revealed that HDL-C, FT3, HCY, and ANC levels were all independently associated with IS risk (Table 3). Both $\mathrm{HCY}$ and ANC levels were positively correlated with IS incidence with respective ORs of 1.518 (95\%CI 1.165-1.977, $P=0.002)$ and 2.418 (95\%CI 1.061-5.511, $P=0.036)$. In contrast, HDL-C and FT3 levels were significantly negatively correlated with IS rates (OR $0.001,95 \% \mathrm{CI}$ $0.000-0.083, P=0.003$ and OR $0.053,95 \%$ CI $0.008-$ $0.326, P=0.002$, respectively).

\section{Discussion}

Herein, we evaluated risk factors for early-onset IS among non-diabetic non-hypertensive patients. We found that IS patients exhibited elevated TG, HCY, WBC, ANC, SBP, and DBP levels, as well as lower HDLC, TC, FT3, and FT4 levels relative to controls. Further analysis revealed that $\mathrm{HCY}$ and ANC levels were positively correlated with IS risk, whereas HDL-C and FT3 levels were negatively correlated with such risk. 
Table 2 Univariate logistic regression model of risk factors for IS in non-diabetic and non-hypertensive young population

\begin{tabular}{|c|c|c|c|c|c|c|}
\hline Parameters & B & SE & Wald & $P$ & $\operatorname{Exp}(B)$ & $95 \% \mathrm{Cl}$ \\
\hline Age, y & .003 & .032 & .006 & .937 & 1.003 & $.942-1.067$ \\
\hline Gender & .000 & .439 & .000 & 1.000 & 1.000 & $.423-2.362$ \\
\hline $\mathrm{BMI}, \mathrm{kg} / \mathrm{m}^{2}$ & .030 & .056 & .288 & .592 & 1.031 & $.923-1.151$ \\
\hline Smoking & -23.446 & 6277.089 & .000 & .997 & .000 & $.000-$ \\
\hline FT3, pmol/L & -1.954 & .311 & 39.493 & .000 & .142 & $.077-.261$ \\
\hline FT4, pmol/L & -.665 & .090 & 54.669 & .000 & .514 & $.431-.613$ \\
\hline TSH, mIU/L & .192 & .144 & 1.792 & .181 & 1.212 & $.915-1.606$ \\
\hline $\mathrm{HDL}-\mathrm{C}, \mathrm{mmol} / \mathrm{L}$ & -4.434 & .832 & 28.376 & .000 & .012 & $.002-.061$ \\
\hline LDL-C, mmol/L & -.166 & .213 & .607 & .436 & .847 & $.559-1.285$ \\
\hline $\mathrm{TC}, \mathrm{mmol} / \mathrm{L}$ & -.804 & .194 & 17.114 & .000 & .447 & $.306-.655$ \\
\hline $\mathrm{TG}, \mathrm{mmol} / \mathrm{L}$ & .449 & .175 & 6.592 & .010 & 1.566 & $1.112-2.206$ \\
\hline $\mathrm{FBG}, \mathrm{mmol} / \mathrm{L}$ & -.035 & .219 & .026 & .872 & .965 & $.628-1.484$ \\
\hline$C R, \mu \mathrm{mol} / \mathrm{L}$ & -.010 & .013 & .580 & .446 & .990 & .966-1.015 \\
\hline UA, $\mu \mathrm{mol} / \mathrm{L}$ & .000 & .002 & .016 & .900 & 1.000 & .996-1.005 \\
\hline $\mathrm{HCY}, \mu \mathrm{mol} / \mathrm{L}$ & .352 & .063 & 31.443 & .000 & 1.422 & $1.257-1.608$ \\
\hline WBC, $10^{9} / \mathrm{L}$ & .351 & .101 & 12.132 & .000 & 1.420 & $1.166-1.730$ \\
\hline ANC, $10^{9} / \mathrm{L}$ & .506 & .136 & 13.861 & .000 & 1.659 & $1.271-2.167$ \\
\hline $\mathrm{ALC}, 10^{9} / \mathrm{L}$ & .096 & .237 & .165 & .685 & 1.101 & $.691-1.754$ \\
\hline $\mathrm{HGB}, \mathrm{g} / \mathrm{L}$ & -.012 & .009 & 1.628 & .202 & .988 & .970-1.006 \\
\hline $\mathrm{PLT}, 10^{9} / \mathrm{L}$ & .006 & .003 & 4.005 & .045 & 1.006 & $1.000-1.013$ \\
\hline $\mathrm{SBP}, \mathrm{mmHg}$ & .066 & .012 & 28.752 & .000 & 1.068 & $1.043-1.094$ \\
\hline $\mathrm{DBP}, \mathrm{mmHg}$ & .064 & .014 & 21.086 & .000 & 1.066 & $1.037-1.096$ \\
\hline
\end{tabular}

$B$ regression coefficient; $S E$ standard error; Exp (B) indicates odds ratio (OR); $C l$ indicates confidence interval; IS, ischemic stroke

Our findings are consistent with those of many other prior analyses which have detected negative correlations between HDL-C levels and IS incidence in young adults. Indeed, while low HDL-C has been linked to elevated IS risk in young populations, LDL-C, TG, and TC levels have been found to be unrelated to such risk [16-18]. These findings are not universal, however, as no significant relationship between HDL-C levels and IS was observed in the ARIC Study [19]. Indeed, some studies have found HDL-C levels to be negatively correlated with vascular events and mortality among IS patients

Table 3 Multivariable conditional logistic regression model of risk factors for IS in non-diabetic and non-hypertensive young population

\begin{tabular}{lllllll}
\hline Parameters & B & SE & Wald & $\boldsymbol{P}$ & Exp (B) & 95\%Cl \\
\hline FT3, pmol/L & -2.945 & .931 & 10.006 & .002 & .053 & $.008-.326$ \\
$\mathrm{HDL}, \mathrm{mmol} / \mathrm{L}$ & -7.134 & 2.367 & 9.083 & .003 & .001 & $.000-.083$ \\
$\mathrm{HCY}, \mu \mathrm{mol} / \mathrm{L}$ & .417 & .135 & 9.574 & .002 & 1.518 & $1.165-1.977$ \\
$\mathrm{ANC}, 10^{9} / \mathrm{L}$ & .883 & .420 & 4.414 & .036 & 2.418 & $1.061-5.511$ \\
\hline
\end{tabular}

$B$ regression coefficient; $S E$ standard error; Exp (B) indicates odds ratio (OR); $C$ I indicates confidence interval; IS ischemic stroke. We used a forward stepwise logistic regression analysis with a statistical variable removal level of $P<0.10$
[20, 21], and one study found elevated HDL-C levels to be correlated with decreased IS severity in patients $\leq 50$ years old, whereas no such relationship was observed among older patients [22]. HDL-C is involved in reverse cholesterol transport, but also plays antithrombotic and anti-inflammatory roles $[23,24]$. In one systematic review, the risk of IS was found to decrease by $11-15 \%$ for every $10 \mathrm{mg} / \mathrm{dL}$ increase in HDL-C [25]. HDL administration has also been found to be neuroprotective, as it is associated with reducing neutrophil recruitment and preserving the blood-brain barrier [26]. Based on our data and these prior studies, we can hypothesize that HDL-C play a key role in mediating IS risk among younger patients, and that preventative efforts aimed at elevating serum $\mathrm{HDL}-\mathrm{C}$ levels in younger adults may significantly decrease IS risk.

We also found that FT3 levels were negatively correlated with IS incidence among young adults. This is the first study to our knowledge to have reported such a relationship, as prior studies and meta-analysis have largely focused on correlations between low FT3 levels and severity/mortality among acute IS patients [27-31]. These prior studies have reported such a relationship even for low FT3 values within the standard reference 
range [32, 33]. One study, however, found that this relationship was age-dependent, such that TT3 and FT3 levels were unrelated to IS outcomes in patients $<65$ years old, whereas TT3 levels were independently predictive of poor outcomes among older patients [34]. In these prior studies, the average population ages ranged from 61.4-81.5 years [27-32], with the exception of one study with a median population age of 48 years [33]. Serum TT3 and FT3 levels are lower among healthy older individuals [35], and FT3 levels decline over time [36]. Age may, therefore, have the potential to confound the effect of FT3 on the cardiovascular system in older individuals, whereas lower FT3 levels in younger patients may be more clinically significant. Triiodothyronine (T3) has been shown neuroprotective effects with a possible mechanism of activation of nitric oxide signaling and vasodilation [37, 38]. Moreover, T3 modulates reorganization of neuronal circuits and synaptic plasticity, motor recovery and functional connectivity during critical periods of recovery after stroke [39]. T3 administration may reduce infarct volume and related edema through the inhibition of aquaporin-4 expression in perimicrovascular astrocytic endfeet [37, 40]. As acute diseases can decrease the conversion of FT4 to FT3 [41], reductions in FT3 levels in acute IS patients may simply be indicative of disease rather than a driver of disease progression. Future research will be essential in order to confirm the mechanistic basis for the observed correlation.

We additionally found that HCY levels were positively correlated with early-onset IS risk. Hyperhomocysteinemia is well known to be associated with elevated IS risk [42]. In line with our findings, many prior studies have confirmed elevated HCY levels to be associated with IS risk in younger patient populations [43-46], with this correlation being strongest in younger individuals [43]. The risk of IS has been shown to be roughly two-fold higher in IS patients with high HCY levels relative to patients with low $\mathrm{HCY}$ levels $[47,48]$. Huang et al. in contrast, determined a $20 \%$ reduction in $\mathrm{HCY}$ level to be linked with a 7\% decrease in IS risk [49]. HCY levels are also correlated with stroke severity, with a poorer prognosis [50, 51], and with stroke recurrence [52]. A $3 \mu \mathrm{mol} / \mathrm{L}$ decrease in total HCY levels was associated with a $10 \%$ reduction in the risk of stroke recurrence [53]. HCY may elevate the risk of IS incidence through mechanisms including the impairment of thrombolysis, thrombosis, enhanced $\mathrm{H}_{2} \mathrm{O}_{2}$ production, endothelial dysfunction, and increased LDL-C oxidation [54-56]. HCY, also, can favor atrial fibrillation occurrence and a subsequent IS (particularly in cardioembolic and cryptogenic strokes) by inducing an electrical and structural atrial remodelling $[57,58]$.

We also found ANC levels to be positively correlated with early-onset IS risk, in line with prior reports that ANC is an independent predictor of IS incidence and recurrence [59-61]. Other studies have also found elevated $\mathrm{ANC}$ values to be related to more severe stroke, poorer stroke outcomes, larger infarct volumes [62, 63], the presence of intracranial atherosclerotic stenosis [64], and unstable carotid plaques [65]. Neutrophils can influence thrombosis and atherosclerosis, thereby modulating the risk of IS $[66,67]$. Neutrophil activation can be reduced by elevated levels of HDL-C and consequent changes in pro-inflammatory cytokine production [68], partially explaining the beneficial impact of HDL-C levels in this context. Neutrophils are key markers of acute inflammation, and are among the first cells recruited following IS [66]. Whether neutrophil accumulation is a response to stroke or a risk factor associated with IS incidence thus requires further investigation.

This study has multiple limitations compared with previous studies that younger strokes showed higher frequency of alcohol abuse, heavy smoking, obesity [69] and physical activity provided metabolic and anti-inflammatory properties [70]. For one, we were not able to account for all possible risk factors pertaining to IS incidence (including nutrition, alcohol intake, and physical inactivity) in this patient population owing to a lack of complete data. For another, we had not evaluated risk factors being influenced by IS subtype (e.g. TOAST classification [71]) distribution for lacking of complete subtypes data. It would be useful to assess the differences among subtypes of IS, particularly between cardioembolic and non-cardioembolic infarction because cardioembolic stroke is the subtype of IS with the highest in-hospital mortality and poor short-term prognosis [72]. Furthermore, we selected controls at random from among health patients, resulting in significant differences in rates of cigarette smoking between the case and control populations that may have significantly impacted the results of our analyses. This was also a retrospective single-center study with a small sample size, potentially biasing our results. Despite these limitations, we believe that these data represent a valuable first step towards understanding risk factors associated with early-onset IS incidence among non-hypertensive and non-diabetic patients.

\section{Conclusions}

Rates of early-onset IS among non-hypertensive nondiabetic patients are rising globally. One of the future lines of research in the study of IS in young people would be its relationship with cerebrovascular risk factors. Our results suggest that $\mathrm{HCY}$ and ANC levels are positively correlated with the risk of early-onset IS, whereas HDL-C and FT3 levels were negatively correlated with such risk. These results provide a valuable framework for future research aimed at understanding how controlling these risk factors may prevent or reduce the risk of IS in younger populations. 


\section{Acknowledgements}

Not applicable.

\section{Authors' contributions}

Conceived and designed the experiments: JL GW. Performed the experiments: NZ LZ QW JZ. Analyzed the data: NZ JL GW. Wrote the paper: NZ JL GW. The author(s) read and approved the final manuscript.

\section{Authors' information}

Not applicable.

\section{Funding}

This work was supported by grants from the Chinese National Natural Science Foundation (No. 81770792) and Key Projects of Science and Technology Planning of Beijing Municipal Education Commission (KZ201810025038) to G.W.; and the Beijing Talents foundation (2018-12) to J.L.

\section{Availability of data and materials}

The data in this study are available from the corresponding author upon reasonable request.

\section{Ethics approval and consent to participate}

The Medical Ethics Committee of Beijing Chaoyang Hospital approved this study, which was consistent with the Declaration of Helsinki, and the requirement for written informed consent was waived due to the retrospective design. Patient data have been de-identified upon data collection

\section{Consent for publication}

Not applicable.

\section{Competing interests}

The authors declare that they have no competing interests.

Received: 21 September 2020 Accepted: 17 November 2020 Published online: 23 November 2020

\section{References}

1. Kissela BM, Khoury JC, Alwell K, Moomaw CJ, Woo D, Adeoye O, et al. Age at stroke: temporal trends in stroke incidence in a large, biracial population. Neurology. 2012;79:1781-7.

2. Singhal AB, Biller J, Elkind MS, Fullerton HJ, Jauch EC, Kittner SJ, et al. Recognition and management of stroke in young adults and adolescents. Neurology. 2013;81:1089-97.

3. Siriratnam P, Godfrey A, O'Connor E, Pearce D, Hu CC, Low A, et al. Prevalence and risk factors of ischaemic stroke in the young: a regional Australian perspective. Intern Med J. 2020;50(6):698-704.

4. Ekker MS, Boot EM, Singhal AB, Tan KS, Debette S, Tuladhar AM, et al. Epidemiology, aetiology, and management of ischaemic stroke in young adults. Lancet Neurol. 2018;17:790-801.

5. Maaijwee NA, Rutten-Jacobs LC, Schaapsmeerders P, van Dijk EJ, de Leeuw FE. Ischaemic stroke in young adults: risk factors and long-term consequences. Nat Rev Neurol. 2014:10:315-25.

6. Maaijwee NA, Rutten-Jacobs LC, Arntz RM, Schaapsmeerders P, Schoonderwaldt HC, van Dijk EJ, et al. Long-term increased risk of unemployment after young stroke: a long-term follow-up study. Neurology. 2014;83:1132-8.

7. Ekker MS, Verhoeven II, Vaartjes I, van Nieuwenhuizen KM, Klijn CJM, de Leeuw FE. Stroke incidence in young adults according to age, subtype, sex, and time trends. Neurology. 2019;92(21):e2444-54.

8. Vangen-Lonne AM, Wilsgaard T, Johnsen SH, Carlsson M, Mathiesen EB. Time trends in incidence and case fatality of ischemic stroke: the tromso study 1977-2010. Stroke. 2015;46:1173-9.

9. Aigner A, Grittner U, Rolfs A, Norrving B, Siegerink B, Busch MA. Contribution of established stroke risk factors to the burden of stroke in young adults. Stroke. 2017:48:1744-51.

10. Boot E, Ekker MS, Putaala J, Kittner S, De Leeuw FE, Tuladhar AM. Ischaemic stroke in young adults: a global perspective. J Neurol Neurosurg Psychiatry. 2020;91(4):411-7.
11. Tuttolomondo A, Maida C, Pinto A. Diabetic foot syndrome: immuneinflammatory features as possible cardiovascular markers in diabetes. World J Orthop. 2015;6(1):62-76.

12. Xu YJ, Tappia PS, Neki NS, Dhalla NS. Prevention of diabetes-induced cardiovascular complications upon treatment with antioxidants. Heart Fail Rev. 2014;19(1):113-21.

13. G, Fava I, Petrella A, Barbieri M, Paolisso G. Cryptogenic stroke and diabetes: a probable link between silent atrial fibrillation episodes and cerebrovascular disease. Expert Rev Cardiovasc Ther. 2014;12(3):323-9.

14. Tuttolomondo A, Maida C, Pinto A. Diabetic foot syndrome as a possible cardiovascular marker in diabetic patients. J Diabetes Res. 2015:2015:268390

15. Pirastehfar M, Katz P, Gentile NT, Jacobi JE, Linares G. Abstract WP208: incidence of ischemic stroke in young adults, a 4 year retrospective review from an urban tertiary Care Center in North Philadelphia. Stroke. 2016;47:AWP208.

16. Lipska K, Sylaja PN, Sarma PS, Thankappan KR, Kutty VR, Vasan RS, et al. Risk factors for acute ischaemic stroke in young adults in South India. J Neurol Neurosurg Psychiatry. 2007;78:959-63.

17. Albucher JF, Ferrieres J, Ruidavets JB, Guiraud-Chaumeil B, Perret BP, Chollet F. Serum lipids in young patients with ischaemic stroke: a case-control study. J Neurol Neurosurg Psychiatry. 2000;69:29-33.

18. Kivioja R, Pietilä A, Martinez-Majander N, Gordin D, Havulinna AS, Salomaa V, et al. Risk factors for early-onset ischemic stroke: a case-control study. J Am Heart Assoc. 2018;7(21):e009774.

19. Shahar E, Chambless LE, Rosamond WD, Boland LL, Ballantyne CM, McGovern PG, et al. Plasma lipid profile and incident ischemic stroke: the atherosclerosis risk in communities (ARIC) study. Stroke. 2003;34:623-31.

20. Yeh PS, Yang CM, Lin SH, Wang WM, Chen PS, Chao TH, et al. Low levels of high-density lipoprotein cholesterol in patients with atherosclerotic stroke: a prospective cohort study. Atherosclerosis. 2013;228:472-7.

21. Mei L, Fang $X, M u ~ L$, Liu H, Zhang H, Qin X, et al. Association of serum high density lipoprotein cholesterol level and risk of recurrent ischemic stroke. Zhonghua Xin Xue Guan Bing Za Zhi. 2014:42:295-300.

22. Sanossian N, Saver JL, Kim D, Razinia T, Ovbiagele B. Do high-density lipoprotein cholesterol levels influence stroke severity ? J Stroke Cerebrovasc Dis. 2006;15(5):187-9.

23. Van der Stoep M, Korporaal SJ, Van Eck M. High-density lipoprotein as a modulator of latelet and coagulation responses. Cardiovasc Res. 2014;103:362-71.

24. Kerry-Anne R. Barter Philip J. Cardioprotective functions of HDLs. J Lipid Res. 2014;55:168-79

25. Amarenco P, Labreuche J, Touboul PJ. High-density lipoprotein-cholesterol and risk of stroke and carotid atherosclerosis: a systematic review. Atherosclerosis. 2008;196:489-96.

26. Lapergue B, Moreno JA, Dang BQ, Coutard M, Delbosc S, Raphaeli G, et al. Protective effect of high-density lipoprotein-based therapy in a model of embolic stroke. Stroke. 2010:41(7):1536-42.

27. Suda S, Shimoyama T, Nagai K, Arakawa M, Aoki J, Kanamaru T, et al. Low free Triiodothyronine predicts 3-month poor outcome after acute stroke. J Stroke Cerebrovasc Dis. 2018;27(10):2804-9.

28. Taroza S, Rastenytė D, Podlipskytė A, Kazlauskas H, Mickuvienè N. Nonthyroidal illness syndrome in Ischaemic stroke patients is associated with increased mortality. Exp Clin Endocrinol Diabetes. 2019. https://doi.org/ 10.1055/a-0915-2015.

29. Zhang S, Zhao X, Xu S, Yuan J, Si Z, Yang Y, et al. Low free triiodothyronineis predicts worsen neurological outcome of patients with acute ischemic stroke: a retrospective study with bioinformatics analysis. BMC Neurol. 2019;19(1):272.

30. Jiang $X$, Xing $H$, Wu J, Du R, Liu H, Chen J, et al. Prognostic value of thyroid hormones in acute ischemic stroke - a meta analysis. Sci Rep. 2017;7(1):16256.

31. Lamba N, Liu C, Zaidi H, Broekman MLD, Simjian R, Shi C, et al. A prognostic role for low triiodothyronine syndrome in acute stroke patients: a systematic review and meta-analysis. Clin Neurol Neurosurg. 2018;169:55-63.

32. Suda S, Muraga K, Kanamaru T, Okubo S, Abe A, Aoki J, et al. Low free triiodothyronine predicts poor functional outcome after acute ischemic stroke. J Neurol Sci. 2016:368:89-93.

33. Feng $X$, Zhou X, Yu F, Liu Z, Wang J, Li Z, et al. Low-normal free triiodothyronine and high leukocyte levels in relation to stroke severity and poor outcome in acute ischemic stroke with intracranial atherosclerotic stenosis. Int J Neurosci. 2019:129(7):635-41.

34. Li LQ, Xu XY, Li WY, Hu X-Y, Lv W. The prognostic value of total T3 after acute cerebral infarction is age-dependent: a retrospective study on 768 patients. BMC Neurol. 2019;19(1):54 
35. van den Beld AW, Visser TJ, Feelders RA, Grobbee DE, Lamberts SW. Thyroid hormone concentrations, disease, physical function, and mortality in elderly men. J Clin Endocrinol Metab. 2005;90(12):6403-9.

36. Strich D, Karavani G, Edri S, Chay C, Gillis D. FT3 is higher in MALES THAN in FEMALES and decreases OVER the lifespan. Endocr Pract. 2017;23(7):803-7.

37. Mdzinarishvili A, Sutariya V, Talasila PK, Geldenhuys WJ, Sadana P. Engineering triiodothyronine (T3) nanoparticle for use in ischemic brain stroke. Drug Deliv Transl Res. 2013;3(4):309-17.

38. Sayre NL, Sifuentes M, Holstein D, Cheng SY, Zhu X, Lechleiter JD. Stimulation of astrocyte fatty acid oxidation by thyroid hormone is protective against ischemic stroke-induced damage. J Cereb Blood Flow Metab. 2017;37(2):514-27.

39. Talhada D, Feiteiro J, Costa AR, Talhada T, Cairrão E, Wieloch T, et al. Triiodothyronine modulates neuronal plasticity mechanisms to enhance functional outcome after stroke. Acta Neuropathol Commun. 2019;7(1):216

40. Sadana P, Coughlin L, Burke J, Woods R, Mdzinarishvili A. Anti-edema action of thyroid hormone in MCAO model of ischemic brain stroke: possible association with AQP4 modulation. J Neurol Sci. 2015;354(1-2):37-45.

41. Wu G-H, Kong F-Z, Cheng Q-Z, Luo W-F, Du X-D. Low T3 syndrome predicts severe neurological deficits of cerebral infarction inpatients with large artery artherosclerosis in internal carotid artery system. Neuro Endocrinol Lett. 2014;35:149-53

42. Kernan WN, Ovbiagele B, Black HR, Bravata DM, Chimowitz MI, Ezekowitz $M D$, et al. Guidelines for the prevention of stroke in patients with stroke and transient ischemic attack: a guideline for healthcare professionals from the American Heart Association/American Stroke Association. Stroke. 2014 45(7):2160-236.

43. Li CJ, Du XX, Yang K, Song LP, Li PK, Wang Q, et al. Effects of professional rehabilitation training on the recovery of neurological function in young stroke patients. Neural Regen Res. 2016;11(11):1766-72.

44. Toyoda K, Uwatoko T, Shimada T, Hagiwara N, Fujimoto S, Ibayashi S, et al. Recurrent small-artery disease in hyperhomocysteinemia: widowers' stroke syndrome? Intern Med. 2004;43(9):869-72.

45. Madonna P, de Stefano V, Coppola A, Cirillo F, Cerbone AM, Orefice G, et al Hyperhomocysteinemia and other inherited prothrombotic conditions in young adults with a history of ischemic stroke. Stroke. 2002;33:51-6.

46. Zhang S, Chang C, Zhang J, Song B, Xu Y. Reconsideration for ischemic stroke risk factors in youth. Zhonghua Yi Xue Za Zhi. 2014;94(25):1936-40.

47. Han L, Wu Q, Wang C, Hao Y, Zhao J, Zhang L, et al. Homocysteine, ischemic stroke, and coronary heart disease in hypertensive patients: a population-based, prospective cohort study. Stroke. 2015;46:1777-86.

48. Wang L, Shen J, Chen CX, Chen ZB, Shen XJ, Song YJ, et al. The association between homocysteine and the different ischemic stroke subtypes: a metaanalysis. Chin J Gerontol. 2018;38:2052-5.

49. Huang X, Li Y, Li P, Li J, Bao H, Zhang Y, et al. Association between percent decline in serum total homocysteine and risk of first stroke. Neurology. 2017:89:2101-7

50. Shi Z, Guan Y, Huo YR, Liu S, Zhang M, Lu H, et al. Elevatedtotal homocysteine levels in acute ischemic stroke are associated with long-term mortality. Stroke. 2015;46(9):2419-25.

51. Kwon HM, Lee YS, Bae HJ, Kang DW. Homocysteine as a predictor of early neurological deterioration in acute ischemic stroke. Stroke. 2014;45(3):871-3.

52. Kumral E, Saruhan G, Aktert D, et al. Association of hyperhomocysteinemia with stroke recurrence after initial stroke. J Stroke Cerebrovasc Dis. 2016; 25(8):2047-54

53. Toole JF, Malinow MR, Chambless LE, Spence JD, Pettigrew LC, Howard VJ, et al. Lowering homocysteine in patients with ischemic stroke to prevent recurrent stroke, myocardial infarction, and death: the vitamin intervention for stroke prevention (VISP) randomized controlled trial. JAMA. 2004;291: 565-75.

54. Pushpakumar S, Kundu S, Sen U. Endothelial dysfunction: the link between homocysteine and hydrogen sulfide. Curr Med Chem. 2014;21:3662-72.

55. Faraci FM, Lentz SR. Hyperhomocysteinemia, oxidative stress, and cerebral vascular dysfunction. Stroke. 2004;35:345-7.

56. Antoniades C, Antonopoulos AS, Tousoulis D, Marinou K, Stefanadis C. Homocysteine and coronary atherosclerosis: from folate fortification to the recent clinical trials. Eur Heart J. 2009;30:6-15.

57. Acampa M, Lazzerini PE, Martini G. Postoperative atrial fibrillation and ischemic stroke: the role of homocysteine. Eur Stroke J. 2018;3(1):92-3.

58. Acampa M, Lazzerini PE, Guideri F, Tassi R, Martini G. Ischemic stroke after heart transplantation. J Stroke. 2016;18(2):157-68.
59. Wu TH, Chien KL, Lin HJ, Hsu HC, Su TC, Chen MF, et al. Total white blood cell count or neutrophil count predict ischemic stroke events among adult Taiwanese: report from a community-based cohort study. BMC Neurol. 2013;13:7.

60. Zia E, Melander O, Bjorkbacka H, Hedblad B, Engström G. Total and differential leucocyte counts in relation to incidence of stroke subtypes and mortality: a prospective cohort study. J Intern Med. 2012;272:298-304.

61. Grau AJ, Boddy AW, Dukovic DA, Buggle F, Lichy C, Brandt T, et al. Leukocyte count as an independent predictor of recurrent ischemic events. Stroke. 2004;35(5):1147-52.

62. Kim J, Song TJ, Park JH, Lee HS, Nam CM, Nam HS, et al. Different prognostic value of white blood cell subtypes in patients with acute cerebral infarction. Atherosclerosis. 2012;222:464-7.

63. Cui LL, Zhang Y, Chen ZY, Su Y-Y, Liu Y, Boltze J. Early neutrophil count relates to infarct size and fatal outcome after large hemispheric infarction. CNS Neurosci Ther. 2020;26(8):829-36.

64. Zhang X, Hou X-H, Ma Y-H, Shen X-N, Cao X-P, Song J-H, et al. Association of peripheral neutrophil count with intracranial atherosclerotic stenosis. BMC Neurol. 2020;20(1):65.

65. Nasr N, Ruidavets JB, Arnal JF, Sie P, Larrue V. Association of neutrophil count with microembolization in patients with symptomatic carotid artery stenosis. Atherosclerosis. 2009:207:519-23.

66. Jickling GC, Liu D, Ander BP, Stamova B, Zhan X, Sharp FR. Targeting neutrophils in ischemic stroke: translational insights from experimental studies. J Cereb Blood Flow Metab. 2015;35(6):888-901.

67. Libby P, Ridker PM, Hansson GK. Progress and challenges in translating the biology of atherosclerosis. Nature. 2011;473:317-25.

68. Carbone F, Nencioni A, Mach F, Vuilleumier N, Montecucco F. Pathophysiological role of neutrophils in acute myocardial infarction. Thromb Haemost. 2013;110(3):501-14.

69. Arboix A, Estevez S, Rouco R, Oliveres M, García-Eroles L, Massons J. Clinical characteristics of acute lacunar stroke in young adults. Expert Rev Neurother. 2015:15(7):825-31.

70. Di Raimondo D, Tuttolomondo A, Buttà C, Casuccio A, Giarrusso L, Miceli G, et al. Metabolic and anti-inflammatory effects of a home-based programme of aerobic physical exercise. Int J Clin Pract. 2013;67(12):1247-53.

71. Pinto A, Tuttolomondo A, Di Raimondo D, Fernandez P, Licata G. Risk factors profile and clinical outcome of ischemic stroke patients admitted in a Department of Internal Medicine and classified by TOAST classification. Int Angiol. 2006;25(3):261-7.

72. Arboix A, Alió J. Acute cardioembolic stroke: an update. Expert Rev Cardiovasc Ther. 2011:9(3):367-79.

\section{Publisher's Note}

Springer Nature remains neutral with regard to jurisdictional claims in published maps and institutional affiliations.

Ready to submit your research? Choose BMC and benefit from:

- fast, convenient online submission

- thorough peer review by experienced researchers in your field

- rapid publication on acceptance

- support for research data, including large and complex data types

- gold Open Access which fosters wider collaboration and increased citations

- maximum visibility for your research: over $100 \mathrm{M}$ website views per year

At $\mathrm{BMC}$, research is always in progress.

Learn more biomedcentral.com/submissions 